\title{
RELAP/SCDAPSIM/MOD3.5 analysis of KIT's QUENCH-14 experiment
}

\author{
Olga Dutkiewicz ${ }^{1,}$, Krzysztof M. Marcinkiewicz $^{1}$, Hiroshi Madokoro ${ }^{2}$, Siarhei Shumski ${ }^{3}$, Chris M. Allison ${ }^{4}$, and \\ Judith K. Hohorst ${ }^{4}$ \\ ${ }^{1}$ Warsaw University of Technology, Institute of Heat Engineering, Nowowiejska 21/25, 00-635 Warsaw, Poland \\ ${ }^{2}$ Karlsruhe Institute of Technology, Hermann-von-Helmholtz-Platz 1, 76344 Eggenstein-Leopoldshafen, Germany \\ ${ }^{3}$ UPC Polytechnic University of Catalonia, Calle Jordi Girona, 1-3, 08-034 Barcelona, Spain \\ ${ }^{4}$ Innovative Systems Software, 3585 Briar Creek Ln, Ammon 83-406, USA
}

Received: 7 June 2017 / Received in final form: 21 July 2017 / Accepted: 7 August 2017

\begin{abstract}
The QUENCH-14 experiment was performed within the ACM series (Advanced Cladding Materials) performed by "Karlsruhe Institute of Technology" (KIT), Germany, to investigate the performance of M5 ${ }^{\circledR}$ cladding material. During the experiment the peak temperatures exceeded $2000 \mathrm{~K}$ (the maximum temperature was estimated at $2249 \mathrm{~K}$ ); therefore, a local melting of the cladding occurred. The experiment was terminated by reduction in the electrical power followed by water injection from the bottom of the test bundle. There was no breakaway oxidation or melt relocation. The test conditions used in the QUENCH-14 were comparable to the QUENCH-6 experiment that used Zircaloy-4. Simulations presented in the article were performed with MATPRO Zircaloy-4 properties and both QUENCH-6 and QUENCH-14 experimental conditions.
\end{abstract}

\section{Introduction}

\subsection{The RELAP/SCDAPSIM/MOD3.5 code}

The RELAP/SCDAPSIM [1] code, designed to predict the behaviour of reactor systems both during normal and accident conditions, is being developed by Innovative Systems Software (ISS) as part of the international SCDAP Development and Training Program (STDP). RELAP/ SCDAPSIM uses the publicly available SCDAP/RELAP5 models and correlations developed by the US Nuclear Regulatory Commission in combination with proprietary features developed by ISS and STDP members, which include more advanced models and correlations. RELAP/ SCDAPSIM/MOD3.5 contains improved models for LWRs such as improved SCDAP models and correlations for fuel rods, B4C control rods, and electrically heated fuel simulator rods used in the CORA, QUENCH, and PARAMETER experimental facilities in Germany and Russia. MOD3.5 is currently being assessed using representative, large-scale integral experiments performed over the past 40 years with results being released in a series of publicly available papers. This assessment is being performed by selected users, ISS, and university students and faculty members participating in the SDTP University Support Program. New versions of MOD3.5 will be released as needed based on the results of the on-going assessment activities.

\footnotetext{
* e-mail: olga.dutkiewicz@outlook.com
}

\subsection{QUENCH-14 experiment}

The QUENCH-14 [2] experiment was performed within the ACM series (Advanced Cladding Materials) performed by "Karlsruhe Institute of Technology" (KIT) in Germany to investigate the performance of $\mathrm{M} 5^{\mathrm{B}}$ cladding material. $\mathrm{M} 5^{\circledR}$ is a material developed by AREVA (former FRAMATOME). During the experiment the peak temperatures exceeded $2000 \mathrm{~K}$ (the maximum temperature was estimated at $2249 \mathrm{~K}$ ); therefore, a local, but only local, melting of the cladding occurred. The experiment was terminated by reduction in the electrical power followed by water injection from the bottom of the test bundle (Fig. 1). There was no breakaway oxidation or melt relocation. The test conditions used in the QUENCH-14 were comparable to the QUENCH6 [3] experiment that used Zircaloy-4. From the comparison of the two experiments it was concluded that Zircaloy-4 and M5 ${ }^{\circledR}$ cladding show comparable behaviour under similar transient test conditions.

Based on the experiment several conclusions were made. Measured hydrogen production was equal to $34 \mathrm{~g}$ during pre-oxidation and transient phases and $6 \mathrm{~g}$ in quench phase. In reference QUENCH-6 experiment has given $32 \mathrm{~g}$ and $4 \mathrm{~g}$ of hydrogen in corresponding phases $[2,4,5]$. Post-experiment examination showed significant cladding inner oxide layers with thickness up to $20 \%$ of outer oxide layers [2] and partially oxidised cladding melt [2]. It can be concluded that M5 ${ }^{\circledR}$ and Zircaloy-4 claddings 


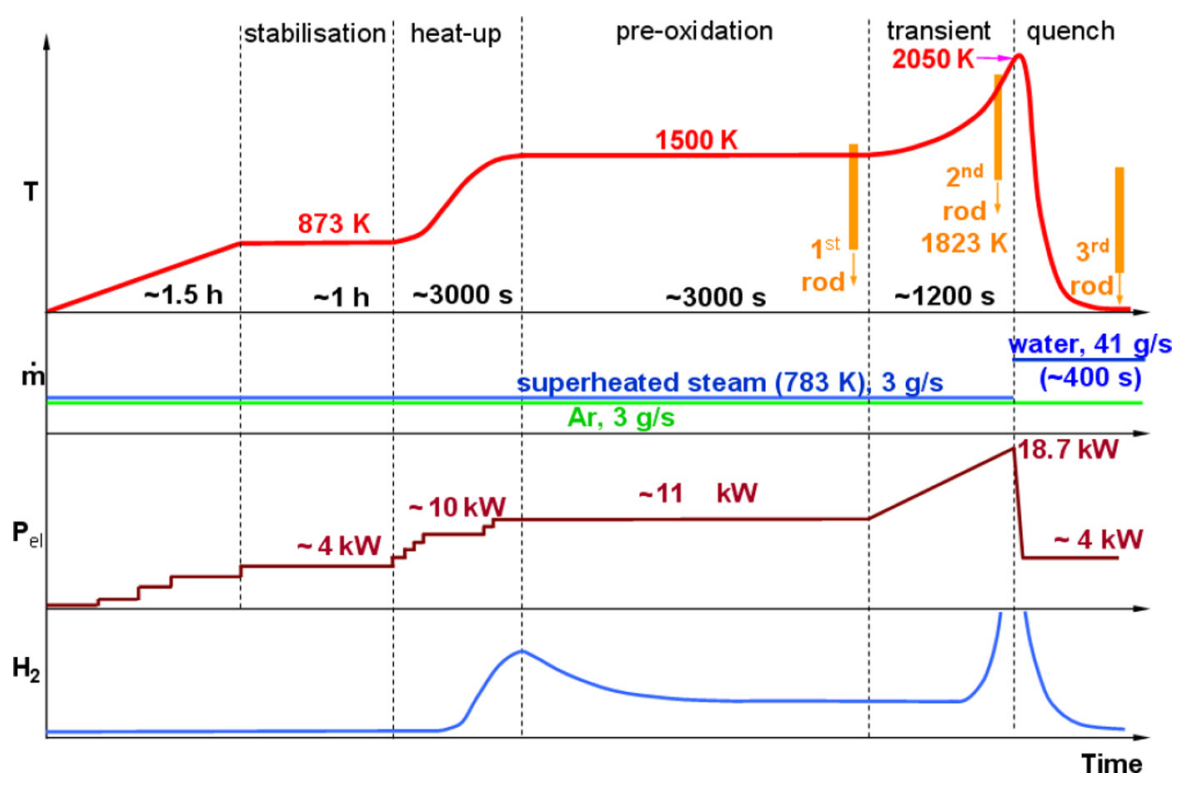

Fig. 1. Phases of the QUENCH-14 experiment [2].

showed comparable behaviour during reflood. $M 5^{\circledR}$ shows superior oxidation resistance over wide temperature ranges and the lower hydrogen uptake in comparison to Zircaloy-4, while at temperatures above $1650 \mathrm{~K}$ Zircaloy reveals lower oxidation rate $[2,4]$. The pre-oxidation phase bundle temperature peaked at $1500 \mathrm{~K}$, for duration of $3000 \mathrm{~s}$, at height $950 \mathrm{~mm}$. Maximal oxide thickness was equal to $170 \mu \mathrm{m}$ (corner rod) [2]. Maximum bundle temperature during transient was equal to $2073 \mathrm{~K}$, with maximal oxide layer thickness of $470 \mu \mathrm{m}$ (corner rod). Rod failure was observed $15 \mathrm{~s}$ before reflood initiation [2]. Shroud failed during reflood and the maximal oxide layer thickness raised up to $630 \mu \mathrm{m}$ [2]. Post-test investigations showed no breakaway oxidation of $\mathrm{M} 5^{\circledR}$ cladding or melt relocation. Some melting occurred at elevations between 900 and $1100 \mathrm{~mm}$. Maximal oxide thickness was equal to $860 \mu \mathrm{m}$ (at elevation $950 \mathrm{~mm}$ ) [2]. Internal oxide layers were formed as result of steam penetrating cladding cracks [2]. Three corner rods made of Zry-4 were withdrawn during the course of the experiment to check their oxidation level and analyse how it develops in various stages of the experiment.

\subsection{QUENCH-14 simulation with RELAP/SCDAPSIM}

The assessment of MOD3.5 for QUENCH-14 has been performed in several phases. The results are being published in a series of papers including this paper. First, the QUENCH-6 experiment was re-analysed using RELAP/SCDAPSIM MOD3.5(dp) version, where (dp) is the configuration control number. This analysis included a careful independent review of the original QUENCH-6 input model that was used to test and validate the improved electrically heated fuel rod simulator model, the re-analysis of the experiment, with the addition of sensitivity studies, and the publication of the results in a series of papers. Second, original QUENCH-6 input model was modified to incorporate the QUENCH-14 features and boundary conditions,
MOD3.5 was then run using the standard "MATPRO" Zircaloy-4 material properties, and the calculated and measured results were compared. To validate the choice of nodalisation used in the simulation sensitivity study has been conducted. It confirmed that the choice was right and accurate. Also the code did not show relevant dependence on the radial nodalisation changes between 13 and 19 radial nodes. These comparisons shown in this paper include the influence of both the slight changes in test conditions between QUENCH-6 and QUENCH-14 as well as the differences in cladding material.

\section{Simulation}

\subsection{Model}

The model representing the experiment has been created as a combination of two parts: RELAP5 hydraulic structure, and core created in SCDAP. The basis for this simulation was formed by an input developed earlier in KIT by Madokoro [6] for QUENCH-6 reference experiment. The new model has included modified heated rods model introduced in RELAP5/SCDAPSIM/MOD3.5 as well as necessary changes in geometry and boundary conditions. Before updating to QUENCH-14 experiment, our model has been evaluated by comparison with both QUENCH-6 [3] and QUENCH-14 [2] reports, and papers analysing the experiments $[4,7,8]$. As seen in Figure 2 the general trends of temperature for QUENCH-6 were well represented with the new model, and the bundle behaviour has been correctly reflected. It is to be noted that during the experiment some thermocouples failed (i.e. at $950 \mathrm{~mm}$ ) and during the reflood some thermocouples were flooded, thus showing sudden drops in measured temperatures (i.e. at $1150 \mathrm{~mm}$ ). Changes in the input model included, but were not limited to: adjusting bypass elevation and collapsed liquid level calculation; also the nodalisation was changed. Of course, we also implemented updated heated rod model. 


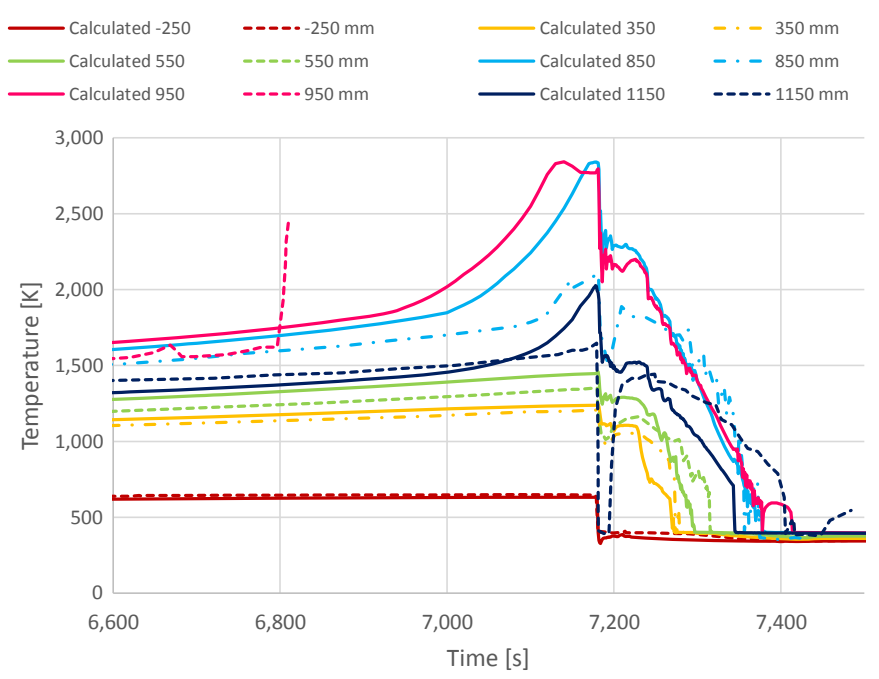

Fig. 2. Comparison of experimental and calculated temperatures for QUENCH-6 experiment of inner fuel rod surface temperature at different axial elevations. Continuous lines show values calculated in RELAP5/SCDAP, while dashed lines represent measured data in the experiment.
The transition from the QUENCH-6 to QUENCH-14 experiment, considering input model, started with changes in the geometry, dimensions and thermohydraulic boundary conditions (Fig. 3).

In our model the RELAP5 elevation begins from $0.00 \mathrm{~m}$, which refers to the $-0.475 \mathrm{~m}$ in the test bundle. SCDAP and RELAP are two separate parts of the model, though the corresponding volumes in both those parts are at the same elevations. In RELAP5 a pipe was created to simulate experimental vessel in which the test bundle was placed. There is one-to-one correspondence between SCDAP axial nodes and RELAP5 volumes, in compliance with the MOD3.5 manual. At the bottom of the pipe there is a lower plenum, simulated by a branch. It is connected with three time-dependant volumes setting boundary conditions. RELAP5 is also used to model the outer cooling jacket. It consists of two parts: one with argon as working fluid and second with water. Those two pipes are connected to sources and sinks setting boundary conditions for proper fluids.

SCDAP model consists of 5 components: unheated central rod, 8 inner rods, 12 outer rods, 4 corner rods and a shroud (Fig. 4).

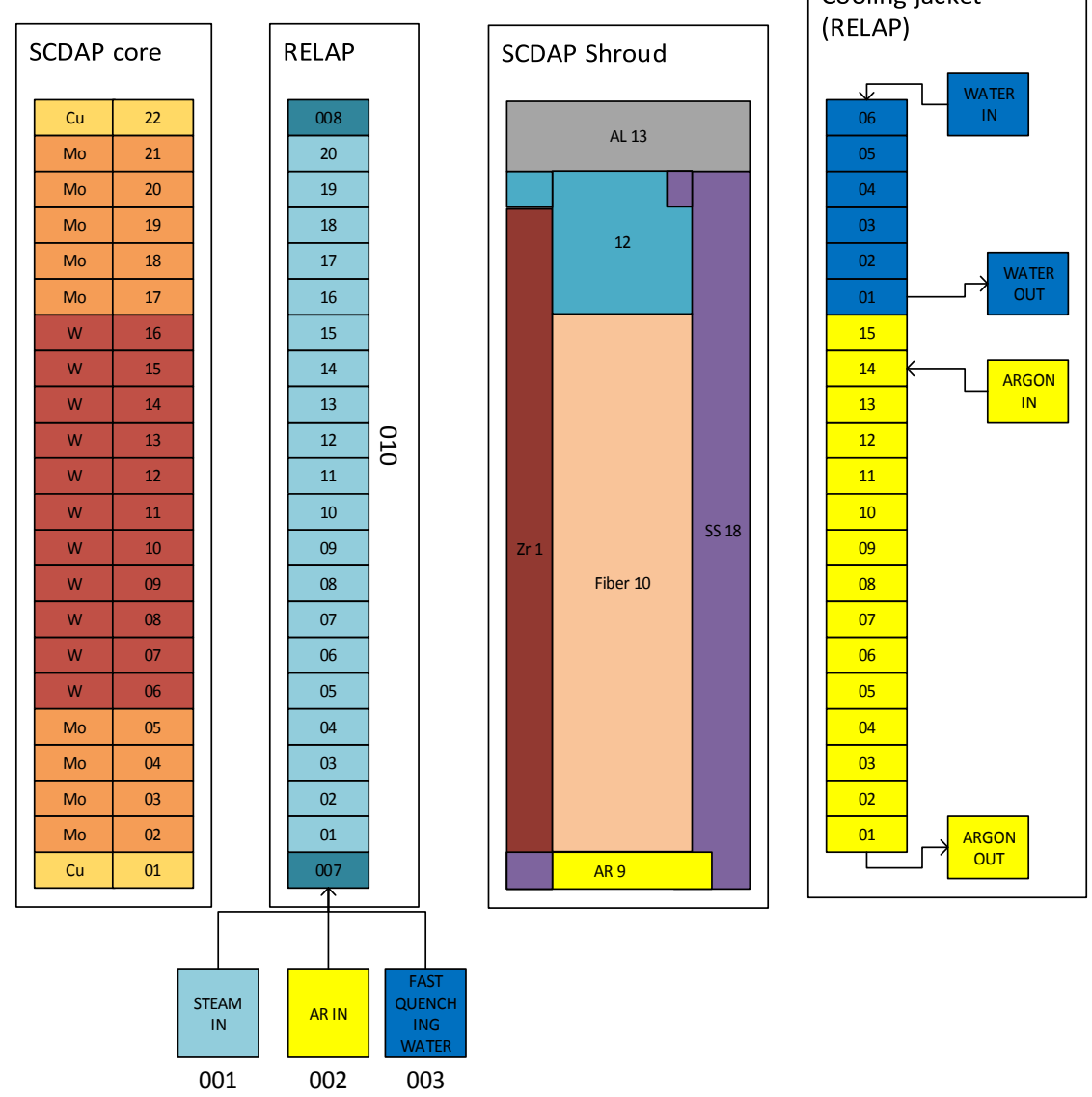

Fig. 3. QUENCH-14 test bundle nodalisation for RELAP5/SCDAP simulation. 


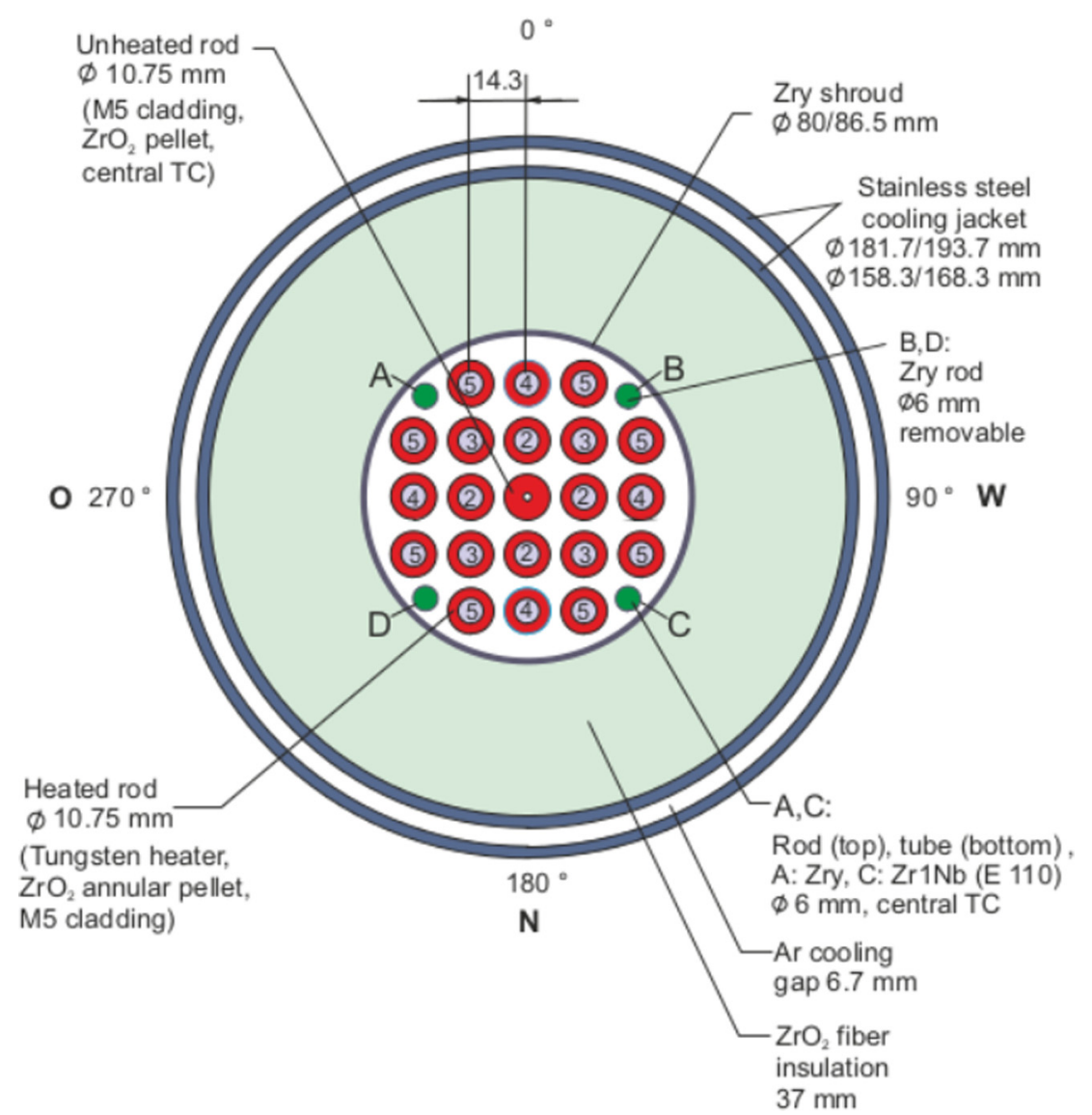

Fig. 4. Fuel rod simulation bundle - cross section [2].

The boundary conditions for this experiment are as follows: flow of steam and argon equal to $3 \mathrm{~g} / \mathrm{s}$, and flow of quenching water is equal to $41 \mathrm{~g} / \mathrm{s}$. Our simulation starts at the beginning of heat-up phase. The temperature is rising from the point of $873 \mathrm{~K}$. At $3110 \mathrm{~s}$ of experiment time preoxidation phase occurs. At $6010 \mathrm{~s}$ the bundle goes into transient phase to be quenched at $7214 \mathrm{~s}$ by initiation of fast water injection. Total available heating power is equal to $70 \mathrm{~kW}$, of which $40 \%$ is within inner heated rods and $60 \%$ in outer rods. Power history used in the simulation is presented in Figure 5.

\section{Results of the analysis and comparison with experiment}

In general the RELAP5/SCDAPSIM/MOD3.5 has proven itself as a good tool for analysis of such problems. It should be noted that following convention has been assumed for next graphs: dashed curves represent data derived from the KIT report [2], while continuous lines represent data calculated by the code.

There is good agreement between results obtained in the simulation and the experiment, especially the axial temperature profiles were impressively similar as in Figure 6 .

There is also good agreement of temperature trends with the experiment in heat-up and transient phases. During reflood the temperature trends are properly

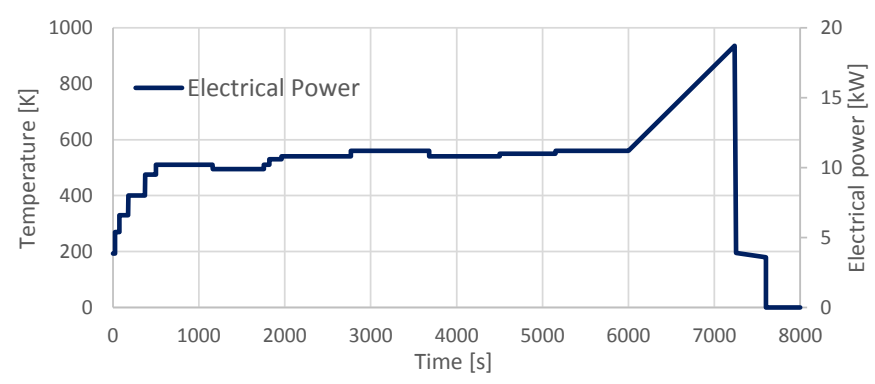

Fig. 5. Power history used in the simulation.

represented, though there are possible small differences due to low resolution of data taken from KIT report or issues with thermocouples themselves (i.e. thermocouple inertia) (Fig. 7).

After verifying that the temperature graphs have proper correlation and seem to correctly represent physical phenomena occurring in the bundle, the focus can be redirected to main issue of QUENCH tests, the hydrogen factor. It appears that general trend of hydrogen generation is properly represented, though there is higher generation rate during heat-up and transient process than in the experiment. During reflood there is an opposite phenomena - hydrogen generation rate is lower than in experiment. It may be caused by presence of thicker protective oxide layer and lower amount of material to produce oxide, since oxide production was higher in heat-up phase. 


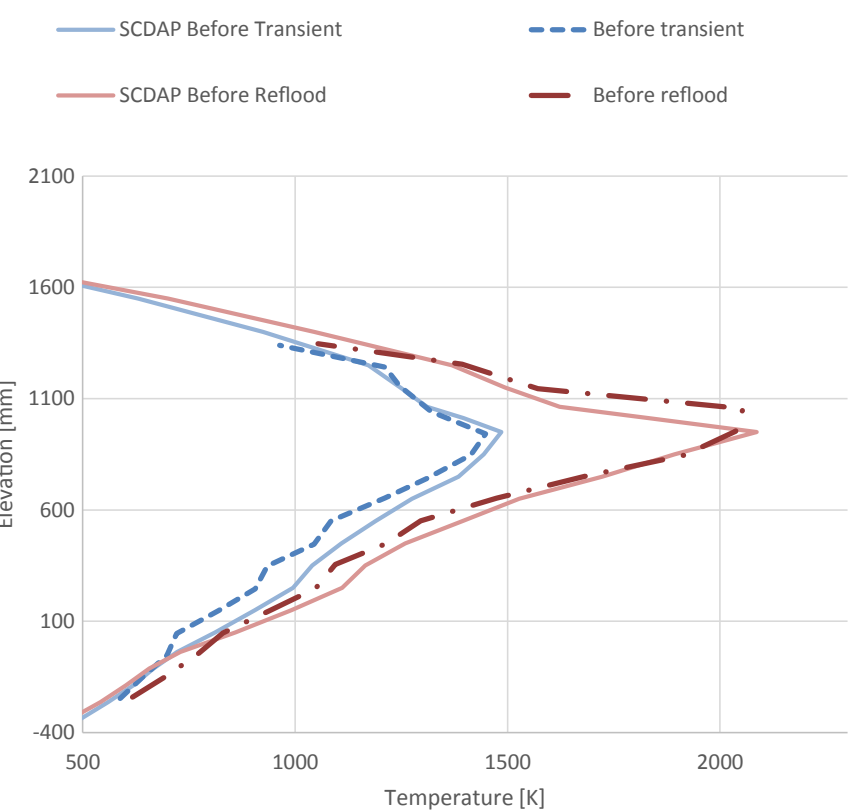

Fig. 6. Axial bundle temperature profiles before transient and before reflood.
Figure 8 presents the integral hydrogen production in three cases: experiment, SCDAP simulation using Zry-4 properties, and SCDAP simulation where Zry-4 oxidation rate correlations were replaced with values for $\mathrm{M} 5{ }^{\circledR}$ based on [9]. Thus we called it M5; however, this material does not have all properties needed for simulation consistent with $\mathrm{M} 5{ }^{\circledR}$. For full specification of the material we would also need its density, specific heat, thermal conductivity, which might be similar to those of Zry-4, but thermal expansion could be significantly different, as one may deduce from [10]. Those properties that would be useful for such simulation were blanked in $[11,12]$ and are not publicly available.

There are visible differences between those two materials. Compared to Zry-4, M5 oxidation rate is significantly lower in the heat-up phase. However, the curve representing M5 oxidation rate reaches lower total hydrogen production value that is further from the experiment.

Figure 9 presents both comparison between SCDAP calculation for QUENCH-14 and measured data for this experiment, and comparison between QUENCH-14 and QUENCH-6. It can be seen that both experiments represent similar oxide layer build-up, which proves what was stated before, that these experiments are comparable.

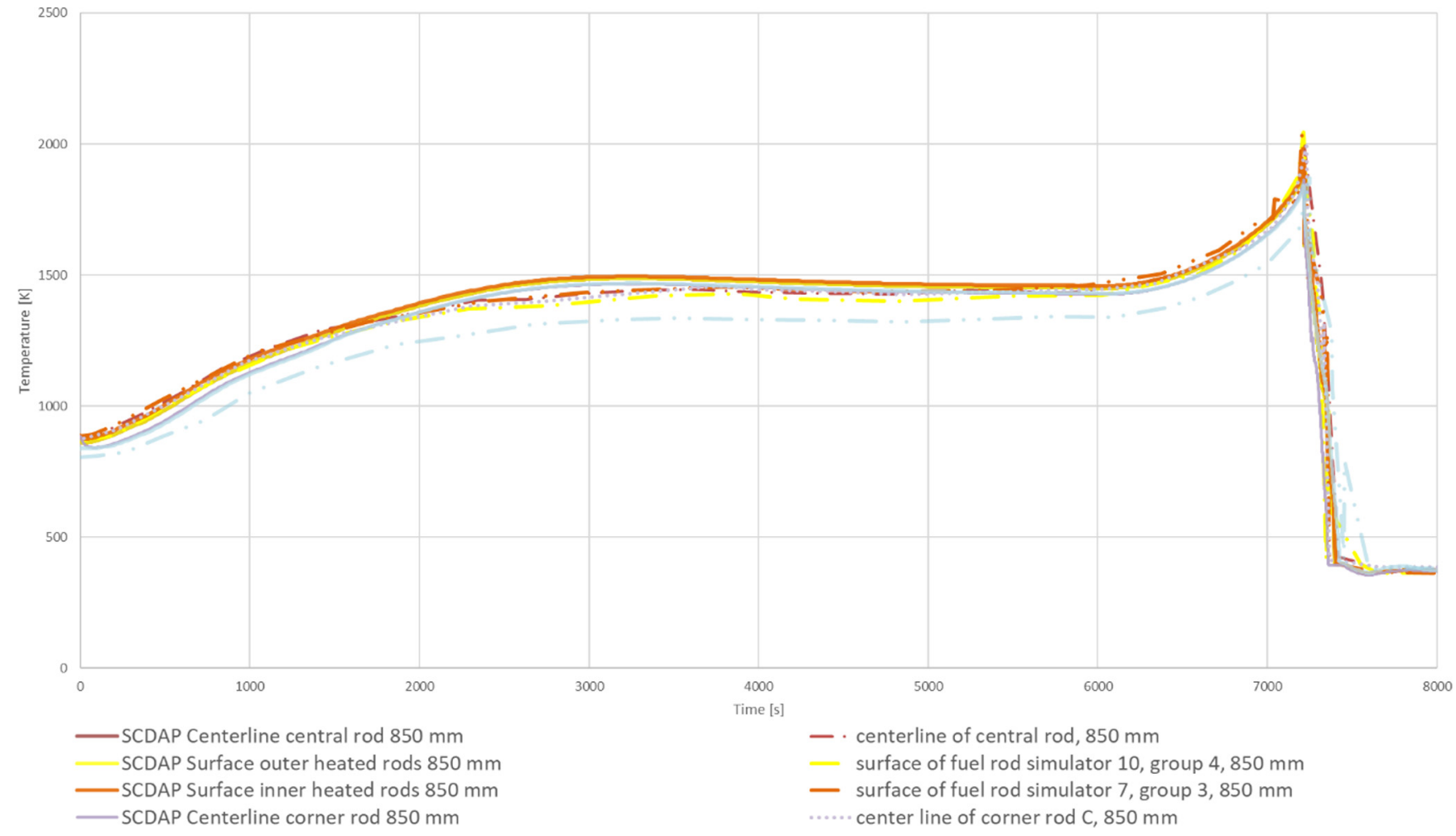

Fig. 7. Thermocouple readings at elevation $850 \mathrm{~mm}$. 


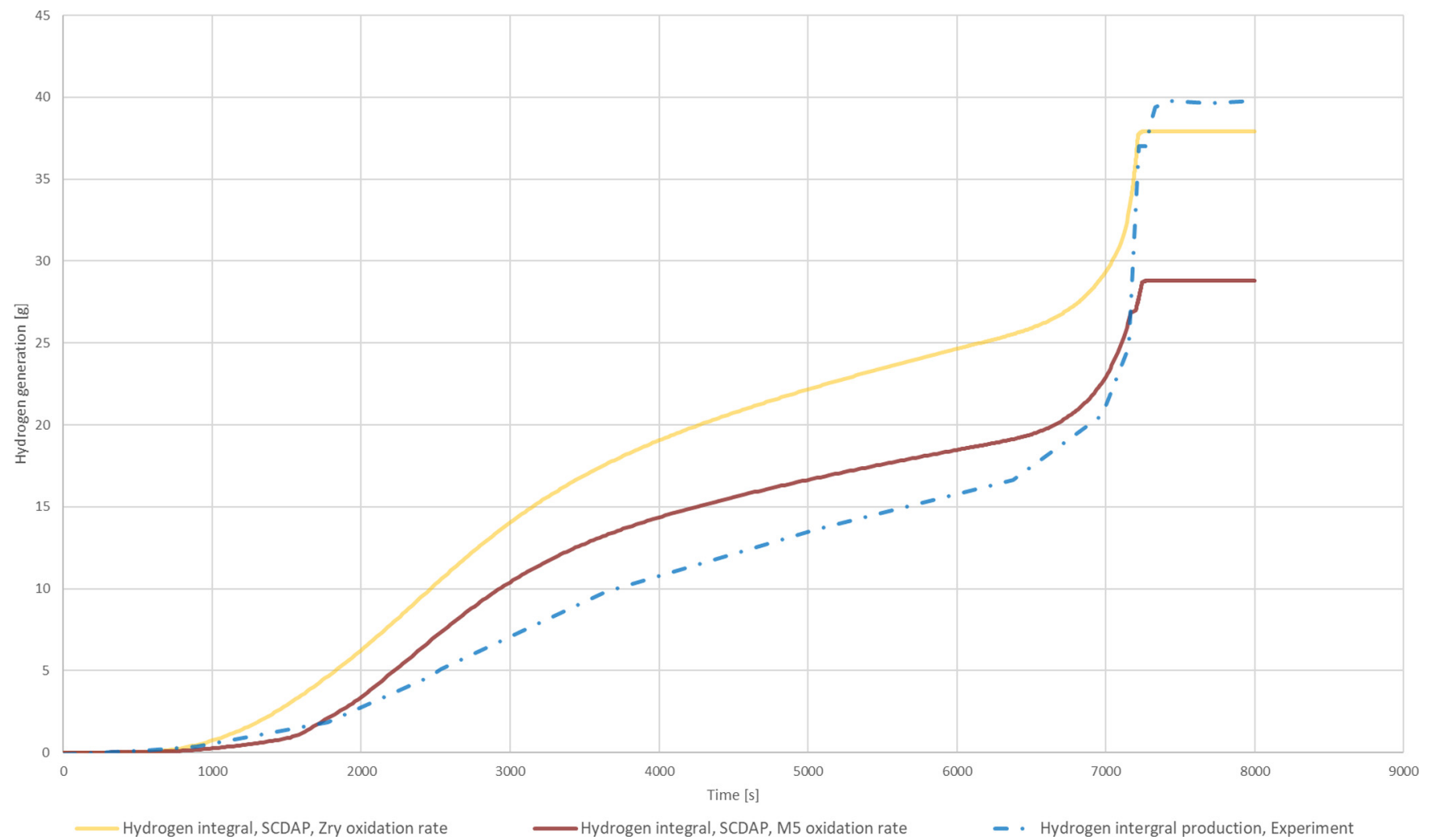

Fig. 8. Comparison of integral hydrogen production.

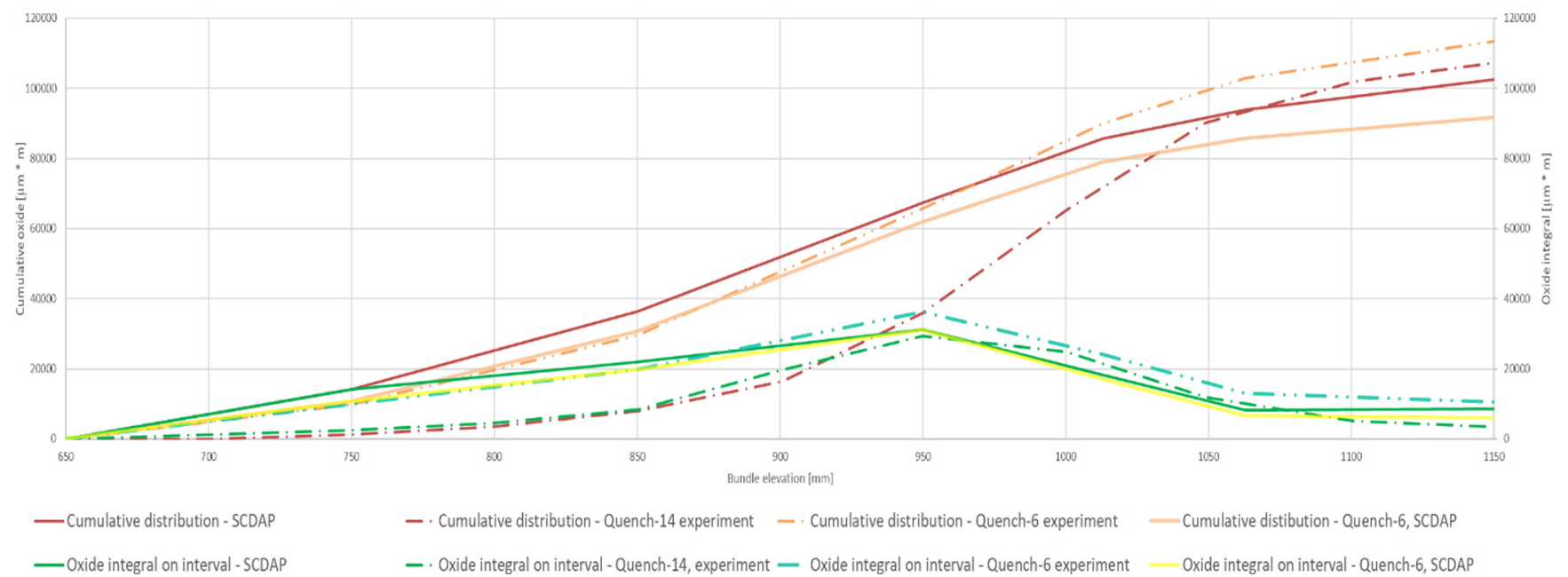

Fig. 9. Cumulative distribution and integrated oxide thickness of corner rod after test made out of Zry-4.

Calculated cumulated oxide layer thickness is thicker than the values measured in the experiment. Oxide thickness is directly connected to the production of hydrogen - therefore conclusions may be linked with those about hydrogen production. Since there is higher hydrogen production in the heat-up phase, also the oxide layer is thicker in SCDAP at the time. The corner rods in the experiment were made out of Zry-4, thus comparison between the oxide thicknesses for those rods seemed the most reasonable. For the corner rods, after the test the axial profile is a little bit different, but the cumulative oxide thickness is basically the same, as seen in Figure 9.

\section{Summary and conclusions}

QUENCH-14 is an experiment within ACM series aimed in investigation of industrial materials, in this case $\mathrm{M} 5{ }^{\circledR}$, especially their properties considering the hydrogen 
production factor. Simulation presented in the article was using Zircaloy-4 material in QUENCH-14 conditions, which gives a chance for a comparison of the materials behaviour in similar temperatures. The model reflected the experiment set-up as well as possible, but some events that occurred during the experiment were not included, such as simulator rod failure $15 \mathrm{~s}$ before reflood initiation, shroud failure during the reflood causing argon flow into annulus between shroud and cooling jacket.

The simulation was performed using RELAP5/ SCDAPSIM/MOD3.5 with updated simulator rod model. Input was prepared basing on proven QUENCH-6 deck prepared by Madokoro [6] with necessary changes connected to different set-up of the test. Before modifying it for the sake of QUENCH-14 analysis, the input was revaluated and properly adjusted.

The results of the analysis are very satisfying. Temperature trends and profiles are represented correctly. It is to be noted that data from thermocouples in experiment are not always to be trusted, because of flooding, inertia and other physical phenomena - therefore trends and profiles should be the main point of concern. And since the agreement is very good, a conclusion can be made that this version of the code is well suited for such analysis and able to perform calculations with good accuracy.

The main model uses Zry- 4 instead of $\mathrm{M} 5{ }^{\circledR}$ and the previously done analysis, by different authors (i.e. [4,8]) as well as the KIT report, state that M ${ }^{\circledR}{ }^{\circledR}$ cladding and Zry-4 should present similar behaviour except for the slight differences in heat-up (ca. $870 \mathrm{~K}$ ) and transient phase (precisely above $1650 \mathrm{~K}$ ) - M $5^{\circledR}$ has accordingly higher and lower hydrogen generation, which can be seen in Figure 8. This fact causes differences in integral hydrogen production and in oxide profiles for heater rods from post-test analysis.

\section{References}

1. Innovative Systems Software, RELAP5 \& RELAP/SCDAPSIM, Idaho, USA, http://www.relap.com/

2. J. Stuckert, U. Stegmaier, M. Steinbrück, Results of Severe Fuel Damage Experiment QUENCH-14 with Advanced Rod Cladding $\mathrm{M} 5{ }^{\circledR}$, KIT Scientific Report 7549 , KIT Scientific Publishing, 2010

3. L. Sepold, W. Hering, C. Homann, A. Miassoedov, G. Schanz, U. Stegmaier, M. Steinbrück, H. Steiner, J. Stuckert, Experimental and Computational Results of the QUENCH-06 Test (OECD ISP-45), Forschunzentrum Karlsruhe Report FZKA 6664, 2004

4. J. Stuckert, M. Große, M. Steinbrück, Bundle reflood tests QUENCH-14 and QUENCH-15 with advanced cladding materials: comparable overview, in 16th QWS, Karlsruhe (2010)

5. T. Haste, F. Fichot, O. Coindreau, Results and conclusions from the Quench integral reflood experiments, in 20th $Q W S$, Karlsruhe (2014)

6. H. Madokoro, N. Erkan, K. Okamoto, Assessment of the models in RELAP/SCDAPSIM with QUENCH-06 analysis, J. Nuclear Sci. Technol. 52, 1417 (2015)

7. J. Birchley, J. Stuckert, Analysis of QUENCH-ACM experiments using SCDAP/RELAP5, in Proceedings of ICAPP'10, San Diego, USA (2010)

8. J. Birchley, B. Jaeckel, T. Haste, M. Steinbrück, J. Stuckert, Analysis of the QUENCH-14 bundle test with $\mathrm{M} 55^{\circledR}$ cladding, in ICONE-17, Brussels, Belgium (2009)

9. M. Grosse, Comparison of the high-temperature steam oxidation kinetics of advanced cladding materials, Nuclear Technol. 170, $272(2010)$

10. V. Garat et al., Quantification of the margins provided by M5 ${ }^{\circledR}$ cladding in accidental conditions, in TopFuel (2012)

11. D. Mitchell, B. Dunn, Evaluation of Advanced Cladding and Structural Material M5 in PWR Reactor Fuel, Framatome, 2000

12. A. Meginnis, C. Brown, Incorporation of M5 Properties in Framatome ANP Approved Methods, 2002

Cite this article as: Olga Dutkiewicz, Krzysztof M. Marcinkiewicz, Hiroshi Madokoro, Siarhei Shumski, Chris M. Allison, Judith K. Hohorst, RELAP/SCDAPSIM/MOD3.5 analysis of KIT's QUENCH-14 experiment, EPJ Nuclear Sci. Technol. 3, 25 (2017) 